\title{
Synthesis of Salt Responsive Spherical Polymer Brushes
}

\author{
Na Su, ${ }^{1}$ Houbin Li, ${ }^{2,3}$ Yu Huang, ${ }^{2}$ and Xiongzhi Zhang ${ }^{4}$ \\ ${ }^{1}$ School of Printing and Packaging Engineering, Shanghai Publishing and Printing College, Shanghai 200093, China \\ ${ }^{2}$ School of Printing and Packaging, Wuhan University, Wuhan 430079, China \\ ${ }^{3}$ State Key Laboratory of Pulp and Paper Engineering, South China University of Technology, Guangzhou 510006, China \\ ${ }^{4}$ College of Chemistry and Molecular Sciences, Wuhan University, Wuhan 430072, China
}

Correspondence should be addressed to Na Su; suna@whu.edu.cn

Received 5 April 2015; Accepted 12 July 2015

Academic Editor: Mircea Chipara

Copyright (C) $2015 \mathrm{Na}$ Su et al. This is an open access article distributed under the Creative Commons Attribution License, which permits unrestricted use, distribution, and reproduction in any medium, provided the original work is properly cited.

A facile preparation of novel salt responsive spherical polymer brushes (SPB) consisting of a carbon spheres core and a shell of sodium polystyrene sulfonate (PSSNa) was described. The SPB were characterized by scanning electron microscopy (SEM), transmission electron microscopy (TEM), Fourier transform infrared spectroscopy (FTIR), and thermogravimetric analysis (TGA). The radius $R$ of carbon spheres and hydrodynamic radius $R_{h}$ of SPB were ca. $370 \mathrm{~nm}$ and $785 \mathrm{~nm}$, respectively. The brushes had $M_{w}$ of $393600 \mathrm{~g} / \mathrm{mol}$ with polydispersity $M_{w} / M_{n}$ of 1.58 . Furthermore, the dependence of PSSNa brushes on ionic strength and $\mathrm{pH}$ was investigated.

\section{Introduction}

Spherical polymer brushes (SPB) are formed by grafting charged polymers densely to the surface of spheres so that polymer chains can stretch away in brush-like conformation [1]. Recently, SPB have attracted wide attention in the field of polymer science due to entirely new properties that come from the strong electrostatic interaction between densely grafted charged chains. This strong electrostatic interaction will lead to a significant stretching of the chains as long as the surrounding medium is a good solvent for the attached polymer chains. However, the swelling of polyelectrolyte brushes may be sensitive to some parameters of the medium such as $\mathrm{pH}$ value, ionic strength, and temperature, which make it a wide range of potential applications in catalysis $[2$, 3], drug delivery [4], protein separation [5], papermaking [6], and printed electronics [7]. Printed electronics technology is based on the principle of printed electronics manufacturing technology [8]. The application in the field of printed electronics $[7,9]$ for SPB is mainly because that the brushlike conformation [1] of SPB can serve as the nanoreactors for conductive nanoparticles [10]. Undoubtedly, the synthesis process and property of SPB are crucial to its application.
For one thing, carbon materials with the intrinsic characteristics of light weight, high thermal resistance, and high strength are widely used in sensing [11], super capacitors [12], and catalysis [13], so SPB with carbon spheres (CS) have become an interesting research object for many researchers. Jin et al. [14] grafted polymers (PMMA, PS, and PGMA) onto the surface of CS by a surface-initiated ATRP process, and the wetting ability and dispersibility of crude CS were improved. Wang et al. [15] modified polystyrene-based activated CS to improve their adsorption properties of dibenzothiophene. Zhang et al. [16] synthesized SPB by grafting poly(diallyl dimethyl ammonium chloride) (p-DMDAAC) on the surface of CS for potential applications in papermaking. Compared to SPB with $\mathrm{SiO}_{2}$ cores we have prepared [17], SPB with CS cores have potential applications in printing electronics because of excellent electrical conductivity of carbon materials.

For another thing, as the nanoreactors of conductive nanoparticles, SPB should have high molecular weight of brushes and controllable swelling behavior. Therefore, salt responsive SPB consisting of a CS core and a shell of sodium polystyrene sulfonate (PSSNa) brushes by surfaceinitiated polymerization (a technique of "grafting from") were synthesized in this paper. In comparison with the molecular 


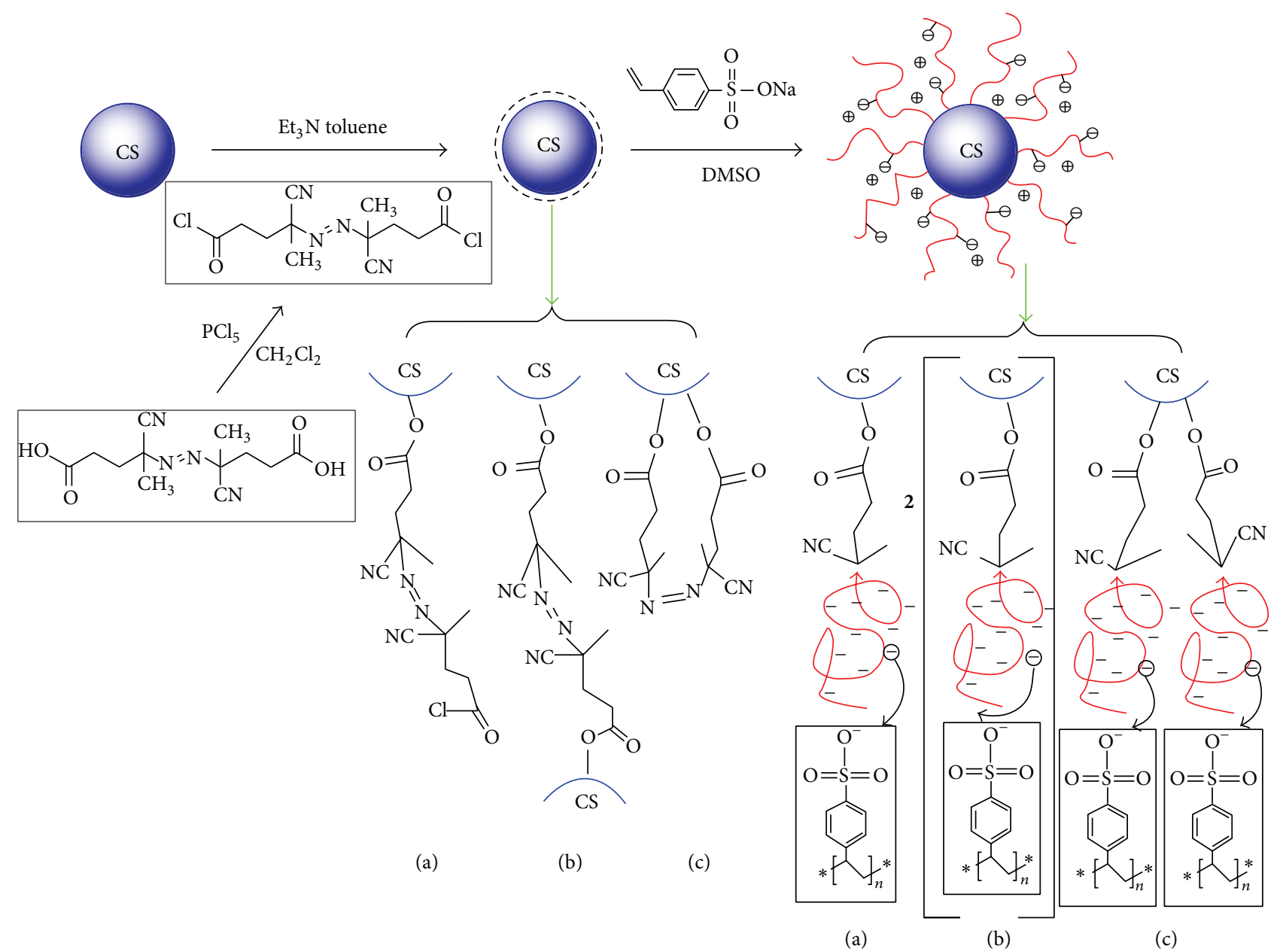

SCHEME 1: Schematic representations of synthesis process of SPB. Number 2 refers to double-ended form grafted on hetero-CS.

weight of brushes by the method of conventional free radical polymerization in our previous work [18], a relatively higher maximum thickness of polymer chains was obtained by this technique and is easily controlled concerning layer thickness, graft density, charge density, and swelling behavior [19]. CS was prepared by hydrothermal method. Compared with other methods such as pyrolysis of hydrocarbons [14], chemical vapor deposition [20], and laser ablation [21], this technique has easy operation, low cost, and low pollution. The synthesis of SPB included two steps (Scheme 1). Azo initiator was firstly initiated to the surface of CS; surfaceinitiated polymerization of sodium 4-vinylbenzenesulfonate monomer was then conducted.

\section{Materials and Methods}

2.1. Materials. 4,4'-Azobis(4-cyanovaleric acid) and sodium 4 -vinylbenzenesulfonate (NaSS) were purchased from Aladdin Reagent Co., Ltd. (Shanghai, China) in analytical grade and used as received. $\mathrm{PCl}_{5}$ was obtained from Shanghai Tingxin Chemical Factory (Shanghai, China). Dichloromethane, toluene, methanol, ethanol, triethylamine, dimethyl sulfoxide (DMSO), and D-(+)-glucose $\left(\mathrm{C}_{6} \mathrm{H}_{12} \mathrm{O}_{6} \cdot \mathrm{H}_{2} \mathrm{O}\right)$ were obtained from Sinopharm Chemical Reagent Co., Ltd. (Shanghai, China). Toluene was refluxed over sodium and dichloromethane was distilled over calcium hydride $\left(\mathrm{CaH}_{2}\right)$ prior to use. All other chemicals were of analytical grade and used without any further treatment.

2.2. Synthesis of Carbon Spheres. $6 \mathrm{~g}$ of glucose was dissolved in $50 \mathrm{~mL}$ deionized water and the solution was sealed in a Teflon-lined stainless steel autoclave and heated at $180^{\circ} \mathrm{C}$ for $6 \mathrm{~h}$. The products were filtered off, washed three times with ethanol and deionized water, respectively, and freeze-dried by freezing at $-30^{\circ} \mathrm{C}$ for $24 \mathrm{~h}$.

2.3. Synthesis of $4,4^{\prime}$-Azobis(4-cyanopentanoyl chloride). $5.6 \mathrm{~g}$ of $4,4^{\prime}$-azobis (4-cyanovaleric acid) $(20 \mathrm{mmol})$ was suspended in $40 \mathrm{~mL}$ dry dichloromethane. The white suspension was cooled to $0^{\circ} \mathrm{C}$ in an ice bath. About $8.32 \mathrm{~g}$ of $\mathrm{PCl}_{5}(40 \mathrm{mmol})$ in $100 \mathrm{~mL}$ dry dichloromethane was added dropwise to the reaction mixture. Then the reaction mixture was allowed to warm up to room temperature and stirred overnight. After several hours, the solution became clear and was concentrated to about $20 \mathrm{~mL}$. A white solid can be obtained by adding $300 \mathrm{~mL}$ cold $\mathrm{n}$-hexane to the concentrated solution. 
The solid was then filtered and dried overnight under vacuum. FTIR (KBr): 2994, 2944, 2240, and $1790 \mathrm{~cm}^{-1} ;{ }^{1} \mathrm{H}$ NMR $\left(\mathrm{CDCl}_{3}, \mathrm{ppm}\right): 2.9-3.2\left(\mathrm{~m}, 4 \mathrm{H}, \mathrm{CH}_{2} \mathrm{CO}\right), 2.4-2.7(\mathrm{~m}, 4 \mathrm{H}$, $\left.\mathrm{CH}_{2} \mathrm{C}\right)$, and $1.7\left(\mathrm{~s}, 6 \mathrm{H}, \mathrm{CH}_{3}\right)$.

2.4. Immobilization of Azo Initiator on Carbon Spheres Surface. $1.0 \mathrm{~g}$ of CS was dispersed in $30 \mathrm{~mL}$ dry toluene followed by addition of $3.17 \mathrm{~g}$ of $4,4^{\prime}$-azobis(4-cyanopentanoyl chloride) and $3 \mathrm{~mL}$ triethylamine. The mixture was stirred at room temperature for $24 \mathrm{~h}$. The products were centrifuged and washed three times with toluene and methanol, respectively, before being dried overnight in a vacuum oven.

2.5. Synthesis of Anionic Spherical Polyelectrolyte Brushes. $1.65 \mathrm{~g}$ of sodium 4-vinylbenzenesulfonate monomer and above azo initiator-immobilized CS were added to $20 \mathrm{~mL}$ DMSO. Polymerization was carried out at $60^{\circ} \mathrm{C}$ for $6 \mathrm{~h}$ under nitrogen atmosphere. The products were then purified and dried in vacuum at $60^{\circ} \mathrm{C}$ for $12 \mathrm{~h}$.

2.6. Characterization. Scanning electron microscopy (SEM) [Quanta 200] and transmission electron microscopy (TEM) [JEM-2100] were used to observe the morphologies of samples. The chemical compositions of samples were analyzed by energy dispersive X-ray spectrometer (EDX) [Quanta 200]. A qualitative structure analysis of SPB was shown from Fourier transform infrared spectroscopy (FTIR) [Nicolet AVATAR 360]. The ${ }^{1} \mathrm{H}$ NMR was measured on a MERCURYVX300 spectrometer (Variant, USA). UV-visible spectrum was recorded in the region of 200-800 nm using UV-3100 spectrometer (Shimadzu, Japan). Thermogravimetric analysis (TGA) was conducted on a SETSYS-1750 at the heating rate of $10^{\circ} \mathrm{C} / \mathrm{min}$ from 25 to $750^{\circ} \mathrm{C}$ under a nitrogen flow. The average initial sample mass was ca. $5.0 \mathrm{mg}$. The weight of all grafted PSSNa brushes $(m)$ could be defined by

$$
m=m_{0} \times \frac{w_{0} \%-w_{1} \%}{w \%-w_{1} \%},
$$

where $m_{0}$ is the weight of SPB used for TGA, $w_{0} \%$ is weight loss of SPB during the temperature from 200 to $800^{\circ} \mathrm{C}, w_{1} \%$ is mass loss of CS in the same temperature, and $w \%$ stands for mass loss of PSSNa brushes.

Gel permeation chromatography (GPC) measurement was carried out on Spectra SERIES P100 to obtain the molecular weight and its distribution in PSSNa brushes. The surface grafting density could be defined as moles of polymer graft per gram $[\mathrm{mole} / \mathrm{g}]$ or per square $\left[\mathrm{mole} / \mathrm{m}^{2}\right]$ of the matrix. Considering the surface area of carbon particles, the calculation of surface grafting density could also be achieved by chains per square nanometer surface. When the average molecular weight $\left(M_{w}\right)$ and the weight of all grafted PSSNa brushes $(m)$ are provided, the surface grafting density $\sigma$ can be calculated using

$$
\sigma=\frac{m}{4 \pi r_{c}^{2} \times M_{w}} .
$$

The hydrodynamic radius $R_{h}$ of SPB and thickness $L$ of brushes were measured by dynamic light scattering (DLS) using zeta potential/particle sizer (Nicomp 380, USA).

\section{Results and Discussion}

3.1. Morphology. The morphologies of CS and SPB are displayed in Figure 1. The CS shows a smooth surface (Figure 1(a)) and the radius $R$ of CS is ca. $370 \mathrm{~nm}$ from DLS result. Unlike the morphologies of CS, an overlayer can be observed in the SEM (Figure 1(b)) and TEM images of SPB (Figures 1(e) and 1(f)), indicating the successful preparation of SPB [14]. The hydrodynamic radius $R_{h}$ of SPB is ca. $785 \mathrm{~nm}$ determined by DLS. The EDX analysis in Figure 1(c) represents the chemical composition of azo initiator-immobilized CS. The signals corresponding to nitrogen and chlorine appear on the spectrum, suggesting that the azo initiator has been immobilized on CS surface.

3.2. FTIR Analyses. Figure 2 shows the FTIR spectra of carbon spheres, azo initiator-immobilized carbon spheres, and SPB. For CS, main peaks at 1705 and $1616 \mathrm{~cm}^{-1}$ are assigned to $\mathrm{C}=\mathrm{O}$ and $\mathrm{C}=\mathrm{C}$ vibrations, respectively. Besides, the bands in the region of 1000-1500 $\mathrm{cm}^{-1}$ (Figure 2(a)), corresponding to the $\mathrm{C}-\mathrm{OH}$ stretching and $-\mathrm{OH}$ bending vibrations, indicate the existence of large numbers of residual hydroxy groups [22]. The absorptions of initiator-immobilized CS at 2240 and $1826 \mathrm{~cm}^{-1}$ are attributed to $-\mathrm{CN}$ stretching vibrations and $\mathrm{C}=\mathrm{O}$ stretching vibration (Figure 2(b)), respectively. It demonstrates that azo initiator has been attached on the surface of CS, which is also supported by the EDX analysis. In the spectra of SPB (Figure 2(c)), asymmetric $\mathrm{SO}_{3}$ stretching bands at 1177 and $1129 \mathrm{~cm}^{-1}$ as well as symmetric $\mathrm{SO}_{3}$ stretching bands at 1043 and $1009 \mathrm{~cm}^{-1}$ can be clearly observed, implying the existence of grafted PSSNa chains [23]. It is noteworthy that $\mathrm{C}=\mathrm{O}$ stretching vibration of $\mathrm{CS}$ at $1705 \mathrm{~cm}^{-1}$ can still be seen in Figure 2(c). All these observations confirm the successful polymerization of SPB by the above method.

3.3. UV-Vis Absorption Spectra Analyses. The UV-vis absorption spectra of carbon spheres, SPB, and PSSNa are presented in Figure 3. No absorption occurs in the UV-vis absorption spectrum of carbon spheres (Figure 3(a)). This is because amorphous carbon in the carbon spheres is synthesized by hydrothermal method [24]. However, two characteristic absorptions of PSSNa at 221 and $256 \mathrm{~nm}$ can be observed in Figure 4(b), belonging to $\pi \rightarrow \pi^{*}$ electron transition from the benzene ring in PSSNa [25]. In the spectrum of SPB (Figure 3(c)), two absorptions of benzene ring from PSSNa are still present, suggesting that the PSSNa chains have been successfully grafted to surface of carbon spheres.

3.4. Thermal Analyses. In order to calculate the weight of grafted PSSNa brushes on the surface of modified CS cores, the thermal gravimetric analysis of samples in a nitrogen atmosphere at $60 \% \mathrm{RH}$ is illustrated (Figure 4). The weight loss below $200^{\circ} \mathrm{C}$ is probably caused by the loss of absorbed water for all the samples. The weight loss of CS between 200 and $800^{\circ} \mathrm{C}$ is about $42.7 \%$ (Figure $4(\mathrm{a})$ ). And the stage from $200^{\circ} \mathrm{C}$ to $400^{\circ} \mathrm{C}$ mainly implies the loss of CS [17]. For pure PSSNa (Figure 4(c)), a 30.5\% weight loss occurs at $200-800^{\circ} \mathrm{C}$. The mass loss from $400^{\circ} \mathrm{C}$ to $450^{\circ} \mathrm{C}$ is mainly 


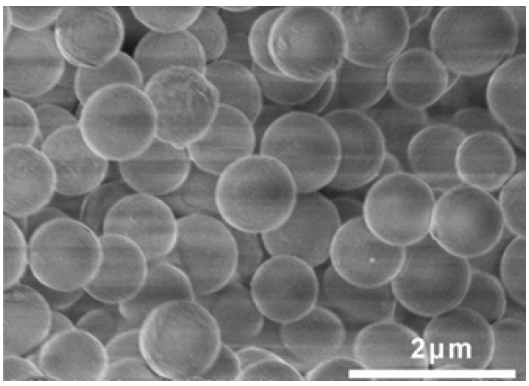

(a)

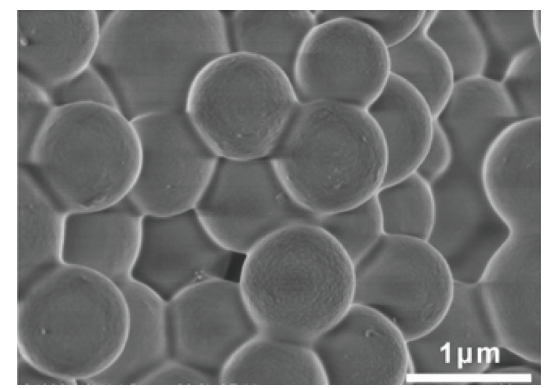

(b)

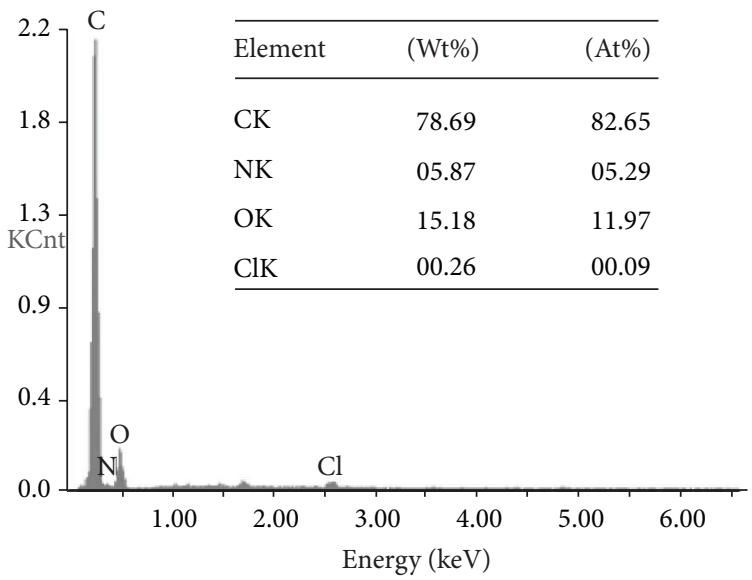

(c)

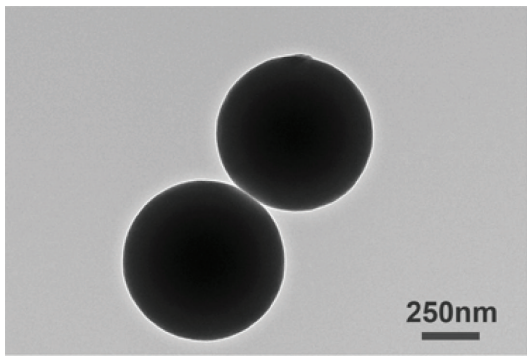

(d)

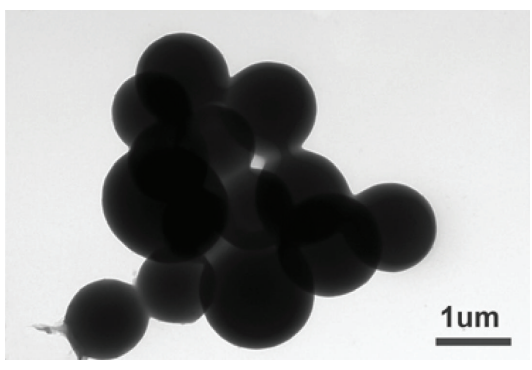

(e)

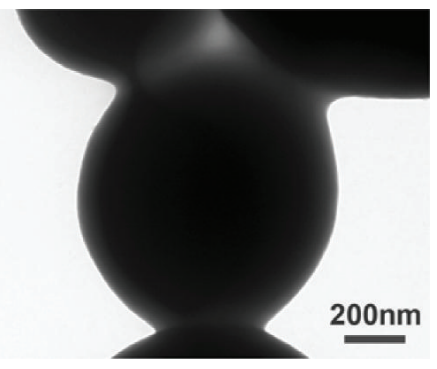

(f)

FIgURE 1: SEM images of (a) CS and (b) SPB; (c) EDX analysis of azo initiator-immobilized CS; TEM images of (d) CS and (e-f) SPB.

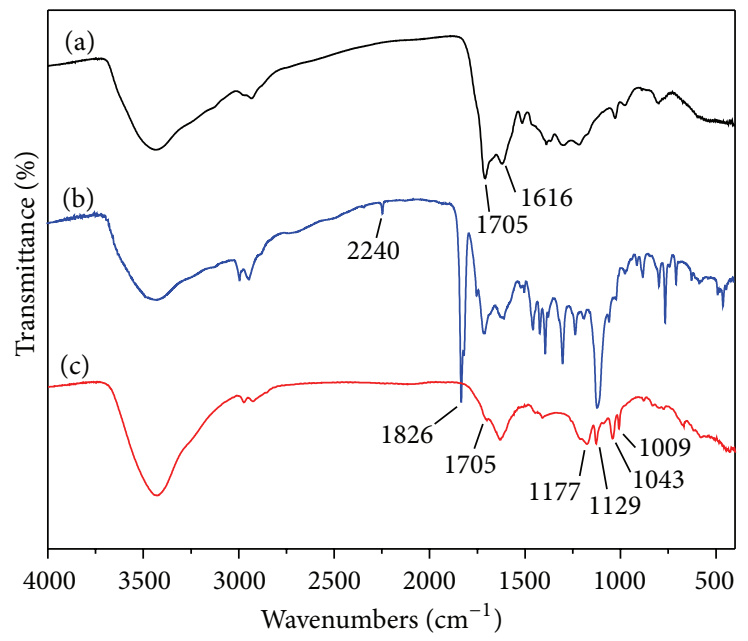

FIGURE 2: FTIR spectra of (a) CS, (b) azo initiator-immobilized CS, and (c) SPB. 


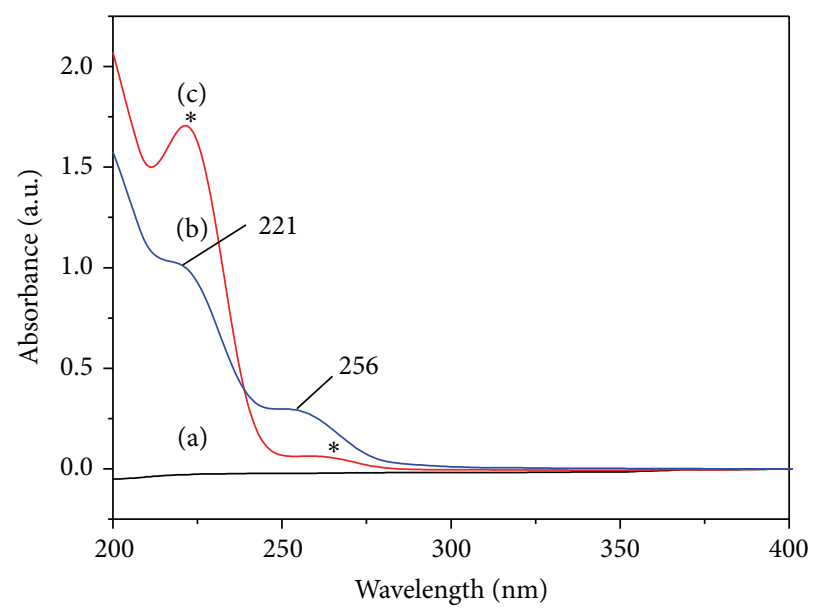

FIGURE 3: UV-vis absorption spectra of (a) carbon spheres, (b) PSSNa, and (c) SPB.
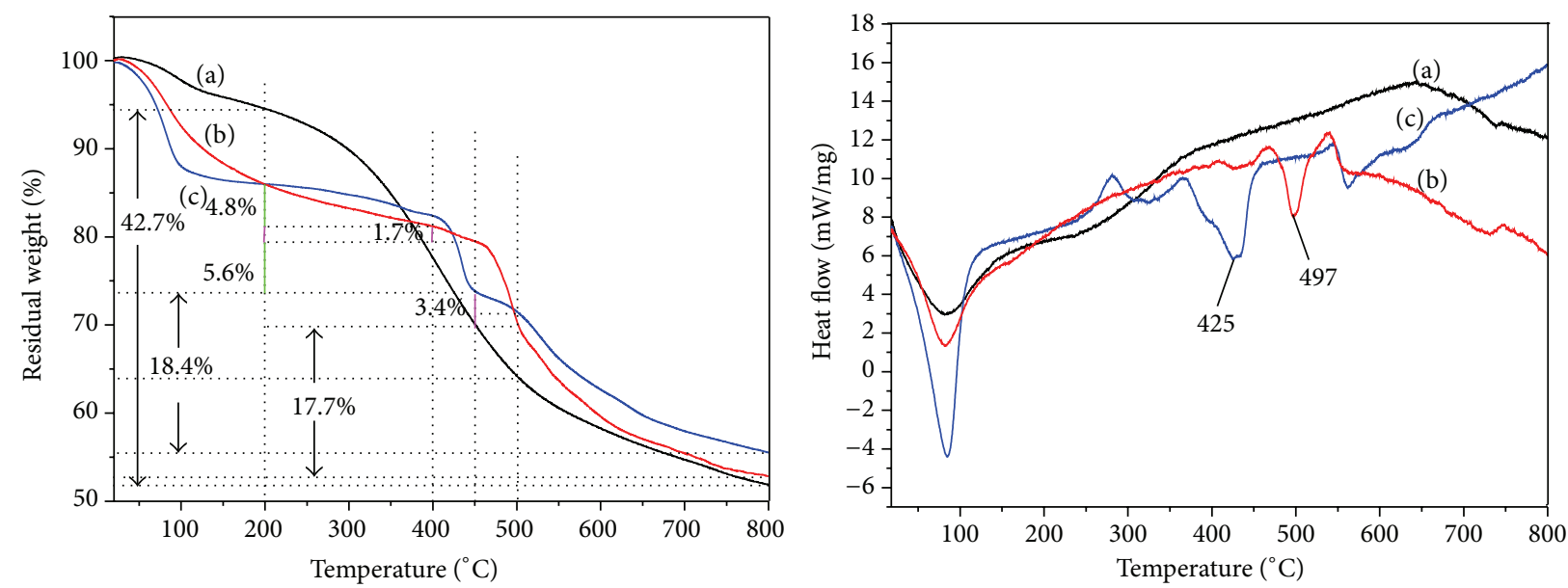

FIGURE 4: Thermal gravimetric analysis of (a) CS, (b) SPB, and (c) PSSNa.

the decomposition of PSSNa [26]. The main thermal decomposition starting at $425^{\circ} \mathrm{C}$ is attributed to the degradation of the polymer backbone.

As shown in Figure 4(b), the weight loss of SPB within the temperature range of 200 to $800^{\circ} \mathrm{C}$ is approximately $33.2 \%$. A $9 \%$ weight loss occurs during the period from $450^{\circ} \mathrm{C}$ to $500^{\circ} \mathrm{C}$. Compared with PSSNa, SPB exhibit higher thermal stability and the major degradation begins at $497^{\circ} \mathrm{C}$. More energy is required, which suggests that the polymer has been bonded to azo initiator-immobilized carbon spheres. The weight of all grafted PSSNa brushes could be calculated from (1).

3.5. Molecular Weight of the Brushes. According to the previous work on similar systems, the molecular weight and its distribution of the brushes are about the same as those of the free polymers [27, 28]. Thus, the free polymers in the solution are collected and purified for GPC determination. Taking $0.1 \mathrm{M} \mathrm{NaCl}(\mathrm{aq})$ as mobile phase, PEG is used as the internal standard at room temperature. The free polymers have $M_{w}$ of $393600 \mathrm{~g} / \mathrm{mol}$ with polydispersity $M_{w} / M_{n}$ of 1.58 . The surface grafting density is $8.38 \times 10^{-9} \mu \mathrm{mol} / \mathrm{nm}^{2}$ according to (2).
3.6. Dependence of Brushes Thickness L on the Ionic Strength and $p H$. The influence of the ionic strength on the swelling behavior of the SPB is investigated by DLS. Figure 5 represents the dependence of zeta potential and brushes thickness $L$ on ionic strength. Here the thickness $L$ can be obtained from the hydrodynamic radius $R_{h}$ and the core radius $R$ of the carbon spheres through $L=R_{h}-R$ [17]. As illustrated in Figure 5, SPB are electrically charged in solution at low salt concentration and a stable dispersion of particles is obtained. Then an increase of salt concentration results in a decrease of absolute value of zeta potential (Figure 5(a)), as well as a decrease of $L$ for both kinds of counterions (Figure 5(b)); moreover, divalent counterions lead to an even more drastic shrinking of brushes. As an increase of salt concentration, dispersions of SPB are no longer stable. The reason for this phenomenon is that the swelling of SPB is dominated by electrostatic repulsive force among the chains, and raising ionic strength by adding large amounts of salt, however, will screen electrostatic interaction and lead to the shrinking of brush layers. Similar results have been obtained in previous theoretical studies [29] and experimental studies [27, 30]. 


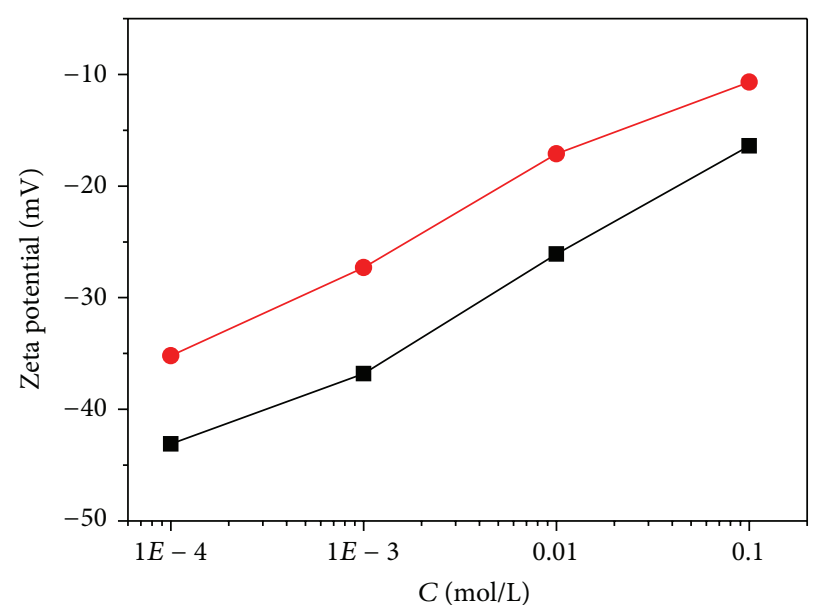

$\mathrm{NaCl}$

$\mathrm{MgSO}_{4}$

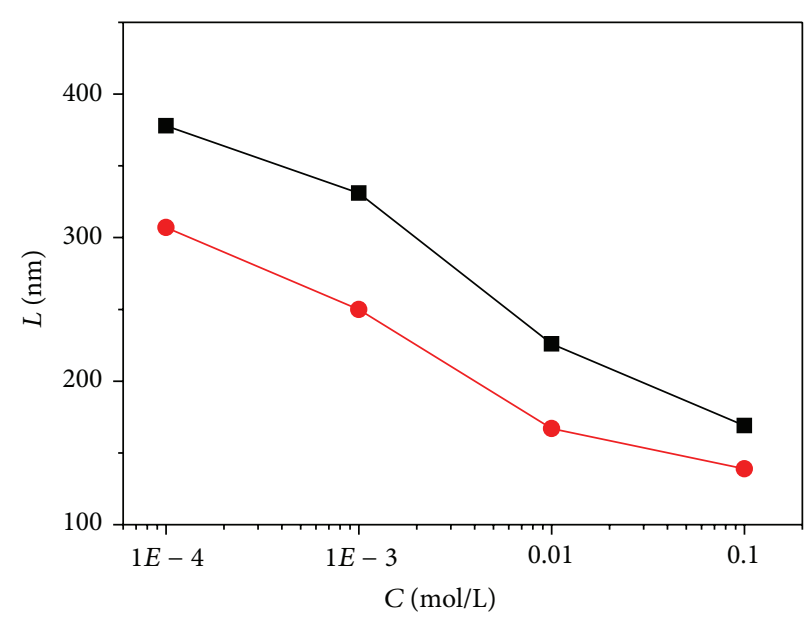

$\mathrm{NaCl}$

$\mathrm{MgSO}_{4}$

(a)

(b)

FIGURE 5: (a) Zeta potential and (b) thickness $L$ of SPB as a function of different concentration of counterions in solution.

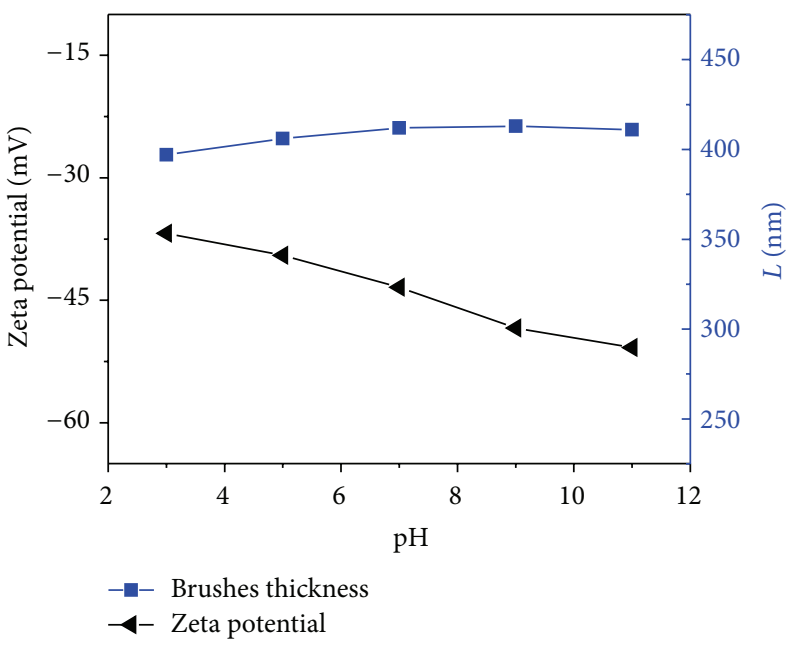

FIGURE 6: Zeta potential and thickness $L$ of SPB as a function of different $\mathrm{pH}$.

The zeta potential and thickness $L$ of SPB in solution with different $\mathrm{pH}$ are shown in Figure 6. SPB are always electrical when the $\mathrm{pH}$ value of solution changes from 3 to 11 and the variation of zeta potential in the solution with different $\mathrm{pH}$ is small. It is also found that change of $\mathrm{pH}$ value has little effect on the thickness of brushes and SPB can be stably dispersed in the solution with different $\mathrm{pH}$. The reason for this is that PSSNa is strong polyelectrolyte and can be completely ionized in solution; thus the change of $\mathrm{pH}$ of solution will not have an impact on the ionization [31].

\section{Conclusions}

The SPB consisting of a carbon spheres core and a shell of PSSNa have been prepared successfully using a technique of "grafting from." Different characterization methods demonstrate that synthesized SPB have well-defined morphology, long polymer chains, and a narrow molecular weight distribution. The shrinking of brushes is sensitive to ionic strength for both monovalent and divalent counterions; moreover, divalent counterions lead to a more drastic shrinking. The change of $\mathrm{pH}$ of solution will not have an impact on the shrinking of brushes.

\section{Conflict of Interests}

The authors declare that there is no conflict of interests regarding the publication of this paper.

\section{Acknowledgments}

This work is supported by Innovation Program of Shanghai Municipal Education Commission (15ZZ112) and National Natural Science Foundational of China (31170558). 


\section{References}

[1] M. Ballauff and O. Borisov, "Polyelectrolyte brushes," Current Opinion in Colloid and Interface Science, vol. 11, no. 6, pp. 316$323,2006$.

[2] J. Chen, P. Xiao, J. Gu et al., "A smart hybrid system of Au nanoparticle immobilized PDMAEMA brushes for thermally adjustable catalysis," Chemical Communications, vol. 50, no. 10, pp. 1212-1214, 2014.

[3] Y. Lu, A. Wittemann, and M. Ballauff, "Supramolecular structures generated by spherical polyelectrolyte brushes and their application in catalysis," Macromolecular Rapid Communications, vol. 30, no. 9-10, pp. 806-815, 2009.

[4] X. Lu, R. Jiang, M. Yang et al., "Monodispersed grafted conjugated polyelectrolyte-stabilized magnetic nanoparticles as multifunctional platform for cellular imaging and drug delivery," Journal of Materials Chemistry B, vol. 2, no. 4, pp. 376386, 2014.

[5] F. Xu, J. H. Geiger, G. L. Baker, and M. L. Bruening, "Polymer brush-modified magnetic nanoparticles for his-tagged protein purification," Langmuir, vol. 27, no. 6, pp. 3106-3112, 2011.

[6] Y. Mei, C. Abetz, O. Birkert, V. Schädler, R. J. Leyrer, and M. Ballauff, "Interaction of spherical polyelectrolyte brushes with calcium carbonate and cellulose fibers: mechanistic studies and their application in papermaking," Journal of Applied Polymer Science, vol. 102, no. 1, pp. 233-241, 2006.

[7] A. N. Korovin, V. G. Sergeyev, O. A. Pyshkina, and L. Tsarkova, "Spherical polyelectrolyte brushes as templates for stable dispersions of polyaniline based conducting particles," Macromolecular Symposia, vol. 317-318, no. 1, pp. 137-141, 2012.

[8] A. Malinauskas, "Chemical deposition of conducting polymers," Polymer, vol. 42, no. 9, pp. 3957-3972, 2001.

[9] Y. Huang, X. Zhang, X. Huang, H. Li, and C. Huang, "Preparation of conductive polypyrrole composite particles based on spherical polyelectrolyte brushes," Materials Express, vol. 5, no. 1, pp. 56-62, 2015.

[10] Y. Lu, Y. Mei, R. Walker, M. Ballauff, and M. Drechsler, "Nanotree'-type spherical polymer brush particles as templates for metallic nanoparticles," Polymer, vol. 47, no. 14, pp. 4985-4995, 2006.

[11] Y. D. Xia and R. Mokaya, "Ordered mesoporous carbon hollow spheres nanocast using mesoporous silica via chemical vapor deposition," Advanced Materials, vol. 16, no. 11, pp. 886-891, 2004.

[12] R. Alcántara, P. Lavela, G. F. Ortiz, and J. L. Tirado, "Carbon microspheres obtained from resorcinol-formaldehyde as highcapacity electrodes for sodium-ion batteries," Electrochemical and Solid-State Letters, vol. 8, no. 4, pp. A222-A225, 2005.

[13] H.-S. Qian, F.-M. Han, B. Zhang, Y.-C. Guo, J. Yue, and B.-X. Peng, "Non-catalytic CVD preparation of carbon spheres with a specific size," Carbon, vol. 42, no. 4, pp. 761-766, 2004.

[14] Y. Z. Jin, C. Gao, H. W. Kroto, and T. Maekawa, "Polymergrafted carbon spheres by surface-initiated atom transfer radical polymerization," Macromolecular Rapid Communications, vol. 26, no. 14, pp. 1133-1139, 2005.

[15] Q. Wang, X. Liang, W. Qiao et al., "Modification of polystyrenebased activated carbon spheres to improve adsorption of dibenzothiophene," Applied Surface Science, vol. 255, no. 6, pp. 34993506,2009 .

[16] Q. Zhang, H. B. Li, P. Zhang, Y. He, and Y. Wang, "Surface modification and characterization of carbon spheres by grafting polyelectrolyte brushes," Nanoscale Research Letters, vol. 9, article 283, 2014.

[17] N. Su, H. B. Li, H. M. Zheng, S. P. Yi, and X. H. Liu, "Synthesis and characterization of poly(sodium-p-styrenesulfonate)/modified $\mathrm{SiO}_{2}$ spherical brushes," eXPRESS Polymer Letters, vol. 6, no. 8, pp. 680-686, 2012.

[18] N. Su and Z. M. Cao, "Preparation and characterization of poly (dimethyl diallyl ammonium chloride)/modified $\mathrm{SiO}_{2}$ spherical brushes," Applied Mechanics and Materials, vol. 731, pp. 569572,2015

[19] H. Zhang and J. Rühe, "Interaction of strong polyelectrolytes with surface-attached polyelectrolyte brushes-polymer brushes as substrates for the layer-by-layer deposition of polyelectrolytes," Macromolecules, vol. 36, no. 17, pp. 6593-6598, 2003.

[20] J.-Y. Miao, D. W. Hwang, K. V. Narasimhulu et al., "Synthesis and properties of carbon nanospheres grown by CVD using Kaolin supported transition metal catalysts," Carbon, vol. 42, no. 4, pp. 813-822, 2004.

[21] Y. Ma, Z. Hu, K. Huo et al., "A practical route to the production of carbon nanocages," Carbon, vol. 43, no. 8, pp. 1667-1672, 2005.

[22] X. Sun and Y. Li, "Colloidal carbon spheres and their core/ shell structures with noble-metal nanoparticles," Angewandte Chemie, vol. 43, no. 5, pp. 597-601, 2004.

[23] A. N. Korovin, V. G. Sergeyev, O. A. Pyshkina et al., "Nanoreactor-assisted polymerization toward stable dispersions of conductive composite particles," Macromolecular Rapid Communications, vol. 32, no. 5, pp. 462-467, 2011.

[24] Y. Zhang, J. Zhang, Y. Zhong et al., "Direct fabrication of organic carbon coated $\mathrm{VO}_{2}(\mathrm{~B})\left(\mathrm{VO}_{2}(\mathrm{~B}) @ \mathrm{C}\right)$ core-shell structured nanobelts by one step hydrothermal route and its formation mechanism," Applied Surface Science, vol. 263, pp. 124-131, 2012.

[25] Q. Zhao, J. Qian, Q. An, and B. Du, "Speedy fabrication of freestanding layer-by-layer multilayer films by using polyelectrolyte complex particles as building blocks," Journal of Materials Chemistry, vol. 19, no. 44, pp. 8448-8455, 2009.

[26] X. Xiao, R. Liu, F. Liu, X. Zheng, and D. Zhu, "Effect of poly(sodium 4-styrene-sulfonate) on the crystal growth of hydroxyapatite prepared by hydrothermal method," Materials Chemistry and Physics, vol. 120, no. 2-3, pp. 603-607, 2010.

[27] H. Zhang and J. Rühe, "Swelling of poly(methacrylic acid) brushes: influence of monovalent salts in the environment," Macromolecules, vol. 38, no. 11, pp. 4855-4860, 2005.

[28] G. K. Raghuraman, J. Rühe, and R. Dhamodharan, "Grafting of PMMA brushes on titania nanoparticulate surface via surfaceinitiated conventional radical and 'controlled' radical polymerization (ATRP)," Journal of Nanoparticle Research, vol. 10, no. 3, pp. 415-427, 2008.

[29] M. Biesalski and J. Rühe, "Scaling laws for the swelling of neutral and charged polymer brushes in good solvents," Macromolecules, vol. 35, no. 2, pp. 499-507, 2002.

[30] X. Guo and M. Ballauff, "Spherical polyelectrolyte brushes: Comparison between annealed and quenched brushes," Physical Review E, vol. 64, no. 5, 2001.

[31] T. Isojima, M. Lattuada, J. B. V. Sande, and T. A. Hatton, "Reversible clustering of $\mathrm{pH}$ - and temperature-responsive Janus magnetic nanoparticles," ACS Nano, vol. 2, no. 9, pp. 1799-1806, 2008 . 

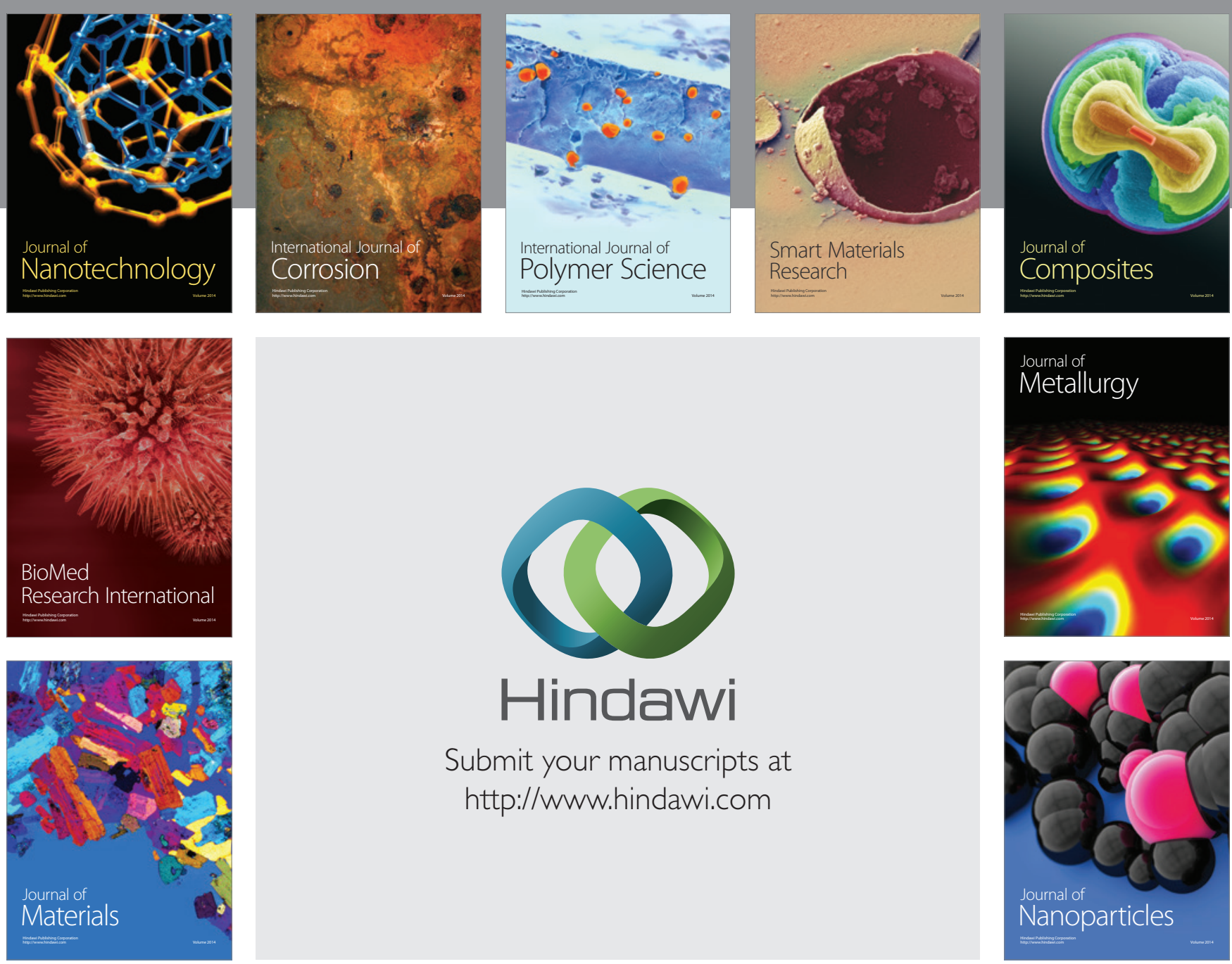

Submit your manuscripts at http://www.hindawi.com
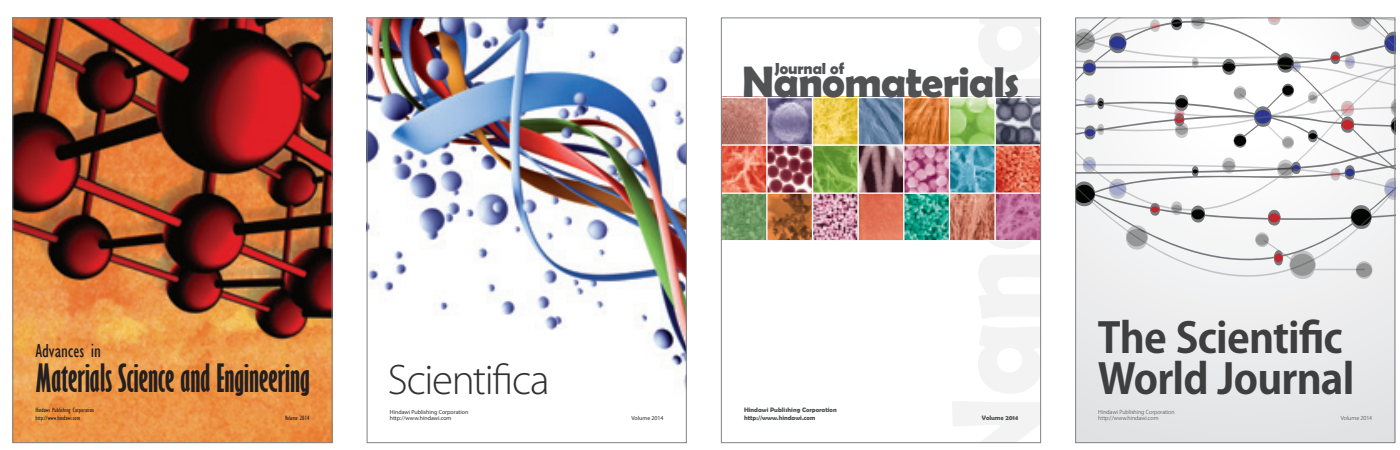

\section{The Scientific World Journal}
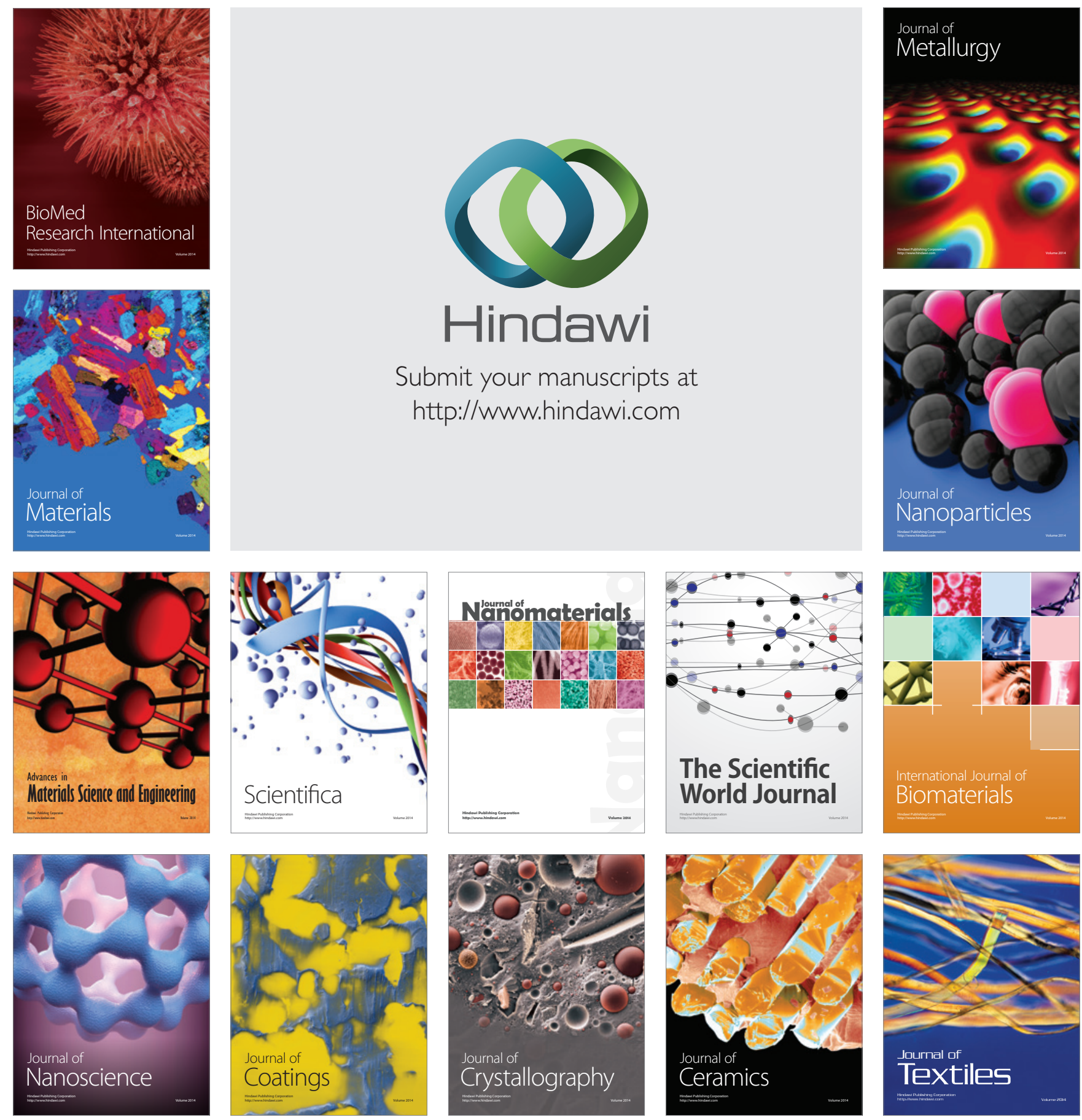